\title{
Synthesis and Characterization of Cockle Shell-Based Calcium Carbonate Aragonite Polymorph Nanoparticles with Surface Functionalization
}

\author{
Syairah Liyana Mohd Abd Ghafar, ${ }^{1}$ Mohd Zobir Hussein, ${ }^{2}$ and Zuki Abu Bakar Zakaria ${ }^{1,3}$ \\ ${ }^{1}$ Institute of Bioscience, Universiti Putra Malaysia, 43400 Serdang, Malaysia \\ ${ }^{2}$ Institute of Advance Technology, Universiti Putra Malaysia, 43400 Serdang, Malaysia \\ ${ }^{3}$ Faculty of Veterinary Medicine, Universiti Putra Malaysia, 43400 Serdang, Malaysia
}

Correspondence should be addressed to Zuki Abu Bakar Zakaria; zuki@upm.edu.my

Received 13 September 2016; Accepted 24 November 2016; Published 1 January 2017

Academic Editor: Vijaya Kumar Rangari

Copyright (C) 2017 Syairah Liyana Mohd Abd Ghafar et al. This is an open access article distributed under the Creative Commons Attribution License, which permits unrestricted use, distribution, and reproduction in any medium, provided the original work is properly cited.

\begin{abstract}
The development of cockle shell-based calcium carbonate aragonite polymorph nanoparticle synthesis method using the technique of mechanical stirring in the presence of dodecyl dimethyl betaine (BS-12) incorporated with surface functionalization demonstrated high homogeneity of sample product with good nanoparticles dispersion. The cockle shell-based calcium carbonate aragonite nanoparticle with functionalized surface was characterized using transmission electron microscopy (TEM), field emission scanning electron microscopy (FESEM), particle size distribution, $\mathrm{pH}$ measurement analysis, Fourier Transform Infrared (FTIR) spectroscopy, and X-ray diffraction (XRD). Surface functionalization was proven to improve the overall size and shape of the nanoparticles and enhance their dispersion properties, preventing coarse agglomeration among nanoparticles in general. The improved method was verified to retain its aragonite crystalline nature. Additionally, surface functionalization did not increase the size of nanoparticles throughout the modification process. This facile preparation using naturally occurring cockle shells as the main source is environmentally friendly because it provides relatively low cost of raw material source as it is abundantly available in nature and has good mineral purity content. Hence, high quality production of surface functionalized cockle shell-based calcium carbonate aragonite polymorph nanoparticles can potentially be exploited and produced on a large scale for various industrial applications, especially for biomedical purposes in the near future.
\end{abstract}

\section{Introduction}

The rapidly burgeoning nanotechnology field has brought a new era of many advances, especially in the development of biomedical engineering field through various challenging research in the last few years. Many studies have been conducted to explore simple, convenient, and costeffective methods to produce nanoparticles from various range of biomaterials for various industrial purposes [1-9]. One of the leading biomaterials which has been intensely investigated is the inorganic calcium carbonate $\left(\mathrm{CaCO}_{3}\right)$ material. In general, it is well documented that calcium carbonate exists in three types of polymorph, which are calcite, aragonite, and vaterite [7-15]. Each of these polymorphisms possesses different properties which determine their special characteristics [5]. In fact, numerous studies on both the physical and chemical properties of calcium carbonate polymorphisms have been accomplished since several decades ago [2, 3, 5, 12-19].

Nonetheless, calcium carbonate aragonite polymorph recently emerges as one of the most popular targets among many scientists for profound exploration in many aspects, especially in the biomedical and pharmaceutical fields $[1,7-$ 10, 20-22]. Moreover, aragonite polymorph of calcium carbonate has been proven to have high potential as a good biomedical material to be integrated, resolved, and replaced by bones owing to its unique characteristics for diverse medical uses $[7,8,11,23]$. Although aragonite is thermodynamically less stable than calcite at ambient temperature and pressure, it is well known to be denser than calcite $[2,6-8,11,17,22]$, 
sensitive towards temperature changes $[13,15,24,25]$, comprising some morphological varieties $[8,11,21,22,25]$, having high mechanical strength $[7,8,22]$, and biocompatible and biodegradable $[7-9,11,21,22,26]$. Hence, this material has become a current focus in many research areas, particularly biomedical research area including targeted drug delivery [22] and bone tissue engineering [10, 20].

From the fabrication of micron-sized calcium carbonate particles in the early days up to the synthesis of desirable nanosized particles today, many studies have used the bottom-up approach via the precipitation process, either through carbonation $[3,5,6,11,18]$ or through solution $[12-$ $14,17,19,24,25,27]$ route for the production of inorganic calcium carbonate raw material over the past few years. However, the new trend of employing nature-based materials such as mineral products $[3,5,6]$ and mineralized organisms $[1,2,7-10,20-22,26]$ to derive calcium carbonate biomaterial has been highly preferable in terms of environmental preservation and efficient use of mineralized seashell byproducts due to its abundance in nature, which can provide raw material source at reasonably low cost and also present good purity of mineral components naturally.

As a matter of fact, a natural marine product, namely, the cockle (Anadara granosa) shell, has been widely reported to have good quality and pure calcium carbonate aragonite polymorph content $[1,4,7,9,10,26]$. Furthermore, it also comprises almost similar mineral composition as bone with high calcium carbon $(\mathrm{CaC})$ content and has no evidence of heavy metal element such as mercury $(\mathrm{Hg})$ or arsenic (As) inside the shell product, which is indeed practical for biomedical uses $[1,4,10,26]$. Therefore, recently, many researchers start to divert their interest from bottom-up synthetic methods to the utilization of nature-based biogenic materials to synthesize calcium carbonate nanoparticles that is generally a top-down approach. In fact, a number of studies have already been carried out to derive calcium carbonate compound from naturally occurring by-product of cockle shells for many purposes, especially to construct various biomedical devices $[10,20,22,26]$.

Directing to the recent trend of synthesizing nanoparticles, a fundamental study by Islam et al. [21] established a basic preparation method to process the solid structure of cockle shells into micron-sized powder and also developed a novel method using simple mechanical stirring in the presence of dodecyl dimethyl betaine or commonly known as BS-12. Several years later, a study by Shafiu Kamba et al. [9] introduced another preparation method to produce cockle shell-based calcium carbonate nanoparticles using a high pressure homogenizer $(\mathrm{HPH})$ technique via the microemulsion route in the presence of a surfactant, namely, polysorbate 80 (Tween 80 ), for anticancer drug delivery purpose. Even though the technique showed promising results for biomedical drug delivery application, it has considerable limitations such as the requirement of complex and expensive equipment with high energy input to operate. Therefore, the simple stirring method by Islam et al. $[8,21]$ appeared as a more appealing and convenient option for simple preparation of calcium carbonate aragonite nanoparticles, especially for large scale production of calcium carbonate aragonite polymorph nanoparticles in the near term. On the other hand, particle's surface modification has been widely documented to improve various physical and chemical aspects of the particles [11, 18, 28-32]. In fact, numerous functional applications of calcium carbonate depend on its controlled surface properties during the synthesis process [11, 13, 24, 2832]. Therefore, the relevance of surface functionalization for cockle shell-based calcium carbonate aragonite polymorph nanoparticles will be herein discussed.

The present work introduces an improved synthesis method to produce cockle shell-based calcium carbonate aragonite polymorph nanoparticle with surface functionalization. In this regard, the current research employs part of the basic procedures established by Islam et al. [8] with improvements in the synthesized technique for the production of cockle shell-based calcium carbonate aragonite polymorph nanoparticles. Furthermore, a specific modification process is also incorporated into the synthesis method to appropriately functionalize the surface of the cockle shell-based calcium carbonate aragonite polymorph nanoparticles. The surface functionalized cockle shell-based calcium carbonate aragonite polymorph nanoparticle is then characterized based on predetermined parameters. We hope that this study can provide fundamental knowledge and broaden new insight into the recent alternative source of calcium carbonate aragonite polymorph nanoparticle derived from biogenic origin of cockle shell by-product that is indeed relevant, convenient, and practical for many industrial applications, especially for biomedical purposes in the near future.

\section{Experimental}

2.1. Preparation of Micron-Sized Cockle Shell-Based $\mathrm{CaCO}_{3}$ Aragonite Particles. The preparation of micrometer-sized particles from cockle shells was done according to the process introduced by Islam et al. [8, 21]. First, the cockle shells were scrubbed and cleaned thoroughly using a metal brush. Then, the cleaned cockle shells were boiled for ten minutes and dried in an oven (Memmert UM500, GmbH Co, Germany) for seven days at $50^{\circ} \mathrm{C}$. After that, the sample was crushed using pestle and mortar (90 mm diameter Agate Top) and ground into powder form using a pulverizing machine (Crusher, RT-08 350G, Taiwan). The powder was then sieved using a $75 \mathrm{~m}$ aperture size of laboratory stainless steel sieve (75 $\mathrm{m}$ Retsch test sieve, Germany) and dried again for 15 hours in the oven. Next, the sample was ground for the second time using pestle and mortar and then dried for seven days in the oven at $50^{\circ} \mathrm{C}$.

2.2. Preparation of Spherical Cockle Shell-Based $\mathrm{CaCO}_{3}$ Aragonite Nanoparticles. The synthesis of spherical cockle shell-based calcium carbonate aragonite nanoparticles from micrometer-sized particles was conducted using an improved method based on previous procedures described by Islam et al. [8]. Dodecyl dimethyl betaine (BS-12) was purchased from Shanghai Jindun Industrial Company, China. Deionized water used in the experiment was obtained from ELGA PURELAB intelligent pure water purification system (Model 
Ultra GE MK2, UK) with $18.2 \mathrm{M}-\mathrm{cm}$ resistivity of water purity. Five grams of cockle shell-based calcium carbonate microparticles was mixed with $50 \mathrm{~mL}$ of distilled water into a $250 \mathrm{~mL}$ conical flask. The suspension was then stirred vigorously at $1200 \mathrm{rpm}$ for an hour at room temperature using a mechanical magnetic stirrer hotplate (WiseStir SMHS, Wisd laboratory instrument, Germany, and magnetic stirrer bar). After that, $1.5 \mathrm{~mL}$ of dodecyl dimethyl betaine (BS12) was added to the suspension after 15 minutes of sonication and stirred again at $1000 \mathrm{rpm}$ for two hours at room temperature. Next, the resulting suspension was centrifuged several times to thoroughly wash out the BS-12 residue from the suspension (Multifuge 3S-R, model D-37520 Osterode, Germany). Subsequently, the sample was dried in an oven for two days at $80^{\circ} \mathrm{C}$ and the sample was then subjected to further steps.

\subsection{Preparation of Surface Functionalized Cockle Shell-Based} $\mathrm{CaCO}_{3}$ Aragonite Nanoparticles. Surface functionalization for spherical cockle shell-based calcium carbonate aragonite polymorph nanoparticles was carried out based on the established method by Huang et al. [30] with some improvements. Calcium chloride dihydrate $\left(\mathrm{CaCl}_{2} \cdot 2 \mathrm{H}_{2} \mathrm{O}\right)$ was bought from Friendemann Schmidt Chemical. An approximately $20 \mathrm{~g}$ of cockle shell-based calcium carbonate aragonite polymorph spherical nanoparticles was suspended into $80 \mathrm{~mL}$ calcium chloride dihydrate solution prepared at 1000 parts per million concentrations into a $250 \mathrm{~mL}$ glass bottle with a cap. After that, the suspension was sonicated three times for 15 minutes each time using an ultrasonic probe (Model 2510, Branson) with a resting period of 20 minutes between sonication treatment intervals. Next, the bottle was tightly sealed and agitated for six hours at $200 \mathrm{rpm}$ on a roller mill machine (Lab Korea) for five days at room temperature. The concentration of calcium ions in the solution was measured each day using a calcium ion selective electrode (Thermo Scientific Orion Ionplus Sure-Flow Calcium Combination ISE Electrode, USA) connected to a potential analyser meter (Eutech Ion 700 Meter, Singapore) with the addition of an appropriate volume of ionic strength adjustor (Thermo Scientific Orion, USA) to provide a constant background ionic strength for the samples and standard concentration measurements. After five days, the sample was washed, centrifuged, and then dried in an oven at $80^{\circ} \mathrm{C}$ for two days.

2.4. Experimental Controls. Besides cockle shell-based calcium carbonate aragonite polymorph spherical nanoparticles without surface modification, calcium carbonate precipitate was also selected as one of the experimental controls. In fact, calcium carbonate precipitate produced from the solution route reaction is often used as the main material to develop many biomedical tools $[27,33,34]$. In the present work, we therefore investigate its crystalline properties in terms of size morphology and also calcium carbonate polymorphism for comparison purposes. The precipitation reaction was performed by stirring $650 \mu \mathrm{L}$ of $5 \mathrm{M}$ calcium chloride solution and $2.5 \mathrm{~mL}$ of $1 \mathrm{M}$ sodium carbonate solution vigorously at $1300 \mathrm{rpm}$ according to the methods published by Ueno et al. [27].
2.5. Physicochemical Characterization. Several instruments were employed for observation and characterization of surface functionalized cockle shell-based calcium carbonate aragonite polymorph nanoparticles. The size and shape of the samples were evaluated using a transmission electron microscopy (Hitachi H-7100, Japan) operated at a voltage of $150 \mathrm{kV}$. The sample was first mixed with absolute alcohol and sonicated using a sonicator (Power Sonic 505, South Korea) for 30 minutes. Then, a drop of the colloidal solution was put onto a carbon-covered copper grid placed on a piece of filter paper and dried at room temperature for an hour. Particle size distribution was performed using a Zetasizer Nano ZS device (Malvern Instrument Ltd., Ver. 6. 12, UK). Each sample was prepared in deionized water and dispersed using an ultrasonicator prior to measurement. The analysis was performed in disposable cuvettes at room temperature with dynamic light scattering detected at $173^{\circ}$ angle. Both hydrodynamic diameter and polydispersity index values were averaged and expressed as mean \pm standard deviation of three replicate measurements. The surface morphology and nanostructure of the sample were examined using a field emission scanning electron microscopy (FESEM, JOEL $7600 \mathrm{~F}$ ) operated at a voltage of $5 \mathrm{kV}$. All the samples were dispersed onto carbon conductive adhesive, placed on sample holder, and then coated with platinum before being examined under the electron microscope. The $\mathrm{pH}$ measurement was conducted using a calibrated $\mathrm{pH}$ meter (Mettler-Toledo) for several samples of micron-sized cockle shell-based calcium carbonate aragonite particles, cockle shell-based calcium carbonate aragonite nanoparticles without surface modification, surface functionalized cockle shell-based calcium carbonate aragonite nanoparticles, and dodecyl dimethyl betaine (BS-12) as well as calcium chloride dihydrate solution of $1000 \mathrm{ppm}$ concentrations. Ten $\mathrm{pH}$ readings of each sample were taken and the mean \pm standard deviation was appropriately calculated. Chemical analyses of the samples were performed using a Fourier Transform Infrared spectrometer (FTIR spectrometer, Model Spectrum 100, PerkinElmer, USA) over the range of 280 to $4000 \mathrm{~cm}^{-1}$ at $2 \mathrm{~cm}^{-1}$ resolution. Crystalline properties of sample products was investigated using an X-ray powder diffractometer (Model PW 3040/60 MPD X'Pert High Pro PANalytical, Philips) equipped with a $\mathrm{Cu} \mathrm{K}(=0.15406 \mathrm{~nm})$ radiation source scanned at a rate of $40 / \mathrm{min}$. The phase of each sample was determined based on diffraction angles of $5^{\circ}$ to $60^{\circ}$ at room temperature.

\section{Results and Discussion}

3.1. Size and Surface Morphology. A number of procedures have been developed to produce nanoparticles with improved size and shape uniformities. The top-down production of nanoparticles began with a breaking-up process that fragmentizes solid cockle shells into nanosized particles via both chemical and mechanical treatments including crushing, grinding, and vigorous stirring methods. Additionally, the synthesis method was improved through the milling process as described earlier in the surface modification procedure. In fact, surface functionalization has been proven to produce better size and shape homogeneities of the cockle shell-based 


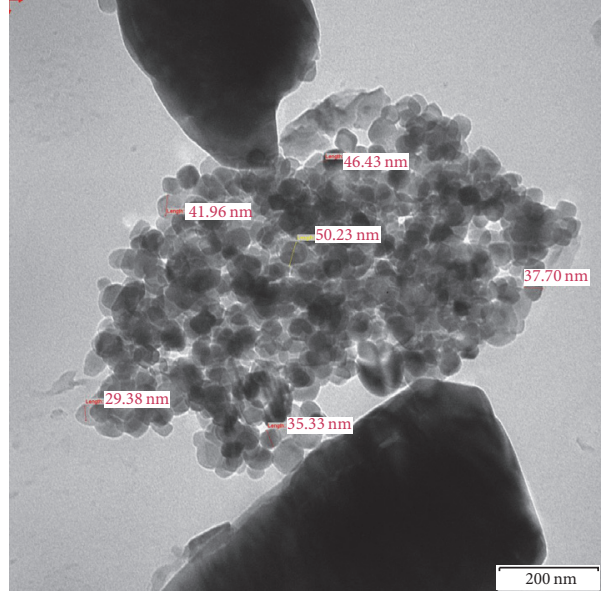

(a)

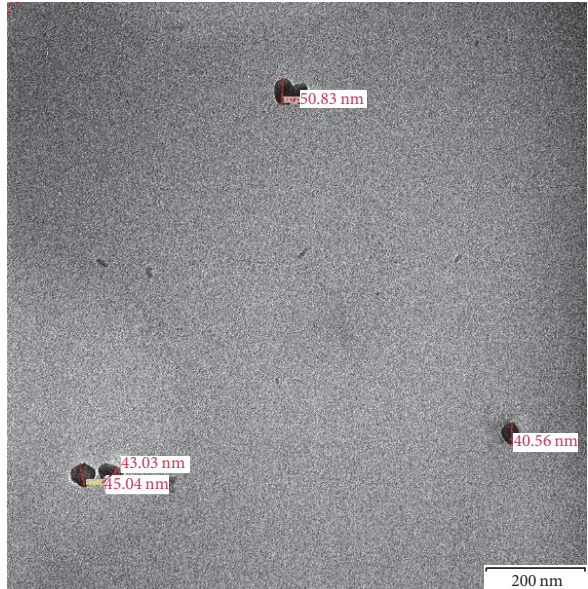

(b)

FIGURE 1: Comparison of transmission electron micrographs between round-shaped cockle shell-based calcium carbonate aragonite nanoparticles (a) without surface modification and (b) after surface modification viewed at 150,000x magnifications.

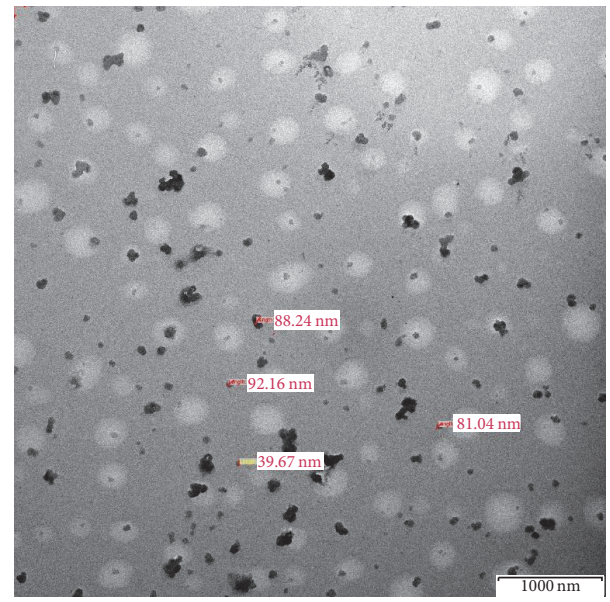

Figure 2: A TEM micrograph on the dispersion of cockle shellbased calcium carbonate aragonite spherical nanoparticles after surface functionalization viewed at 20,000x magnifications.

calcium carbonate nanoparticle with improved nanoparticle dispersion, which is particularly important for many biomedical purposes [35].

Figures 1(a) and 1(b) provide a comparison between cockle shell-based calcium carbonate aragonite nanoparticles before and after surface functionalization based on size and morphology. The transmission electron micrographs (TEM) indicated that the size and shape of the nanoparticles were uniformly improved and yet surface functionalization did not increase the size of the cockle shell-based calcium carbonate aragonite nanoparticles in general. Moreover, the surface functionalized cockle shell-based calcium carbonate aragonite nanoparticles were also observed to be more dispersed compared to those without surface modification as portrayed in Figures 1(a) and 1(b), respectively.

Figure 2 shows an overall view of the surface functionalized cockle shell-based calcium carbonate aragonite

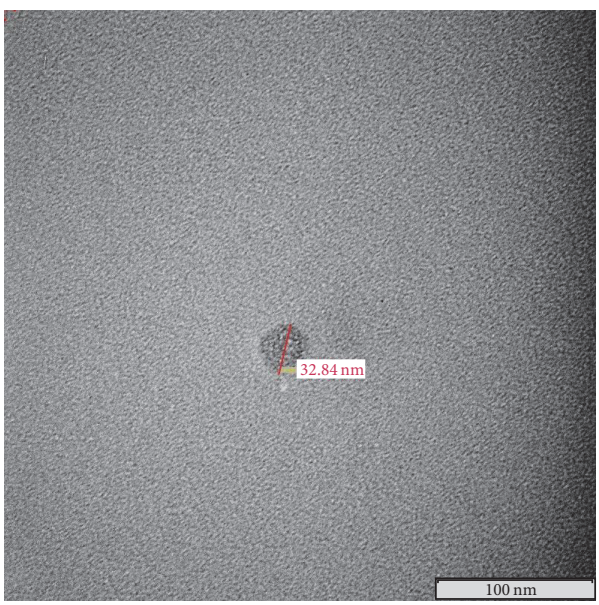

FIGURE 3: A TEM micrograph focusing on a single round-shaped surface functionalized cockle shell-based calcium carbonate aragonite viewed at 300,000x magnifications.

spherical nanoparticles examined with the transmission electron microscope at low magnification. This figure provides a larger picture of the general distribution of the cockle shellbased calcium carbonate aragonite spherical nanoparticles after surface functionalization at low microscopic magnification. In fact, the overall size, shape, and dispersion of the surface functionalized cockle shell-based calcium carbonate aragonite nanoparticles were homogeneously reduced and improved through the milling process after the surface modification procedure. In addition, Figure 3 presents an evident image that focuses on a single surface functionalized cockle shell-based calcium carbonate aragonite nanoparticle examined at a very high magnification with the transmission electron microscope. The figure clearly displays a detailed view on its round shape, provides an average size of a single nanoparticle, and also demonstrates the porous structure 
TABLE 1: $Z$-average diameter $(\mathrm{nm})$ and polydispersity index of cockle shell-based calcium carbonate aragonite polymorph nanoparticles after surface functionalization expressed in mean \pm standard deviation.

\begin{tabular}{lcc}
\hline Sample & $\begin{array}{c}\text { Z-average } \\
\text { diameter, } \\
\text { mean } \pm \text { SD }(\mathrm{nm})\end{array}$ & $\begin{array}{c}\text { Polydispersity index } \\
(\mathrm{PDI}), \\
\text { mean } \pm \text { SD }\end{array}$ \\
\hline $\begin{array}{l}\text { Surface functionalized } \\
\begin{array}{l}\text { cockle shell-based calcium } \\
\text { carbonate aragonite } \\
\text { polymorph nanoparticles }\end{array}\end{array}$ & $133.0 \pm 5.9$ & $0.40 \pm 0.07$ \\
\hline
\end{tabular}

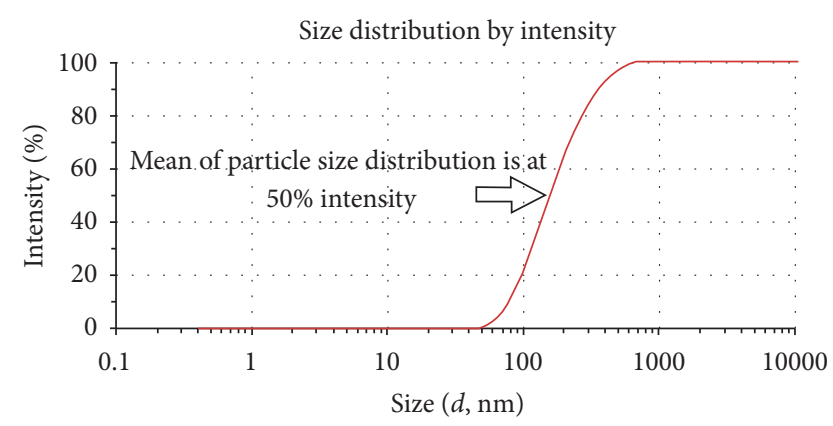

FIGURE 4: Cumulative plot graph of size distributions of intensity (\%) against diameter ( $\mathrm{nm}$ ) of the surface functionalized cockle shellbased calcium carbonate aragonite nanoparticles.

characteristic of the cockle shell-based calcium carbonate aragonite polymorph nanoparticle in general.

On the other hand, the particle size distribution of the surface functionalized cockle shell-based calcium carbonate aragonite nanoparticles is portrayed in a cumulative graph of intensity (\%) versus diameter as shown in Figure 4, whereas Table 1 displays the $Z$-average diameter and polydispersity index of the surface functionalized cockle shell-based calcium carbonate aragonite nanoparticles expressed in mean \pm standard deviation based on three replicates of independent experiment. The mean cumulative distribution is seen at $50 \%$ intensity in the graph. In fact, the value is statistically very similar to the average value concept in which, in this study, it is the calculated value for the average size distribution of the surface functionalized cockle shell-based calcium carbonate aragonite nanoparticles in deionized water. Therefore, the average size of the surface functionalized cockle shell-based calcium carbonate aragonite nanoparticles by Zetasizer was found to be $133.0 \mathrm{~nm} \pm 5.9$ as shown in Table 1 , which is slightly higher than that obtained using transmission electron microscopy.

Practically, the $Z$-average value shown in the particle size distribution analysis refers to the hydrodynamic diameter of the nanoparticles. In fact, several factors could contribute to these variations, such as the different technique during preparation, types of solvent used for characterization, and physical measurement conditions as well as the amount of measured samples in the respective procedures. Regardless of the differences, all methods have been widely recognized to produce reliable and good quality experimental results. Yet, most of the time, the experiments are very dependable on individual preparation skills. Indeed, the variation in the nanoparticle size distribution results from multiple experimental methods can provide additional information based on many different perspectives in order to develop a comprehensive and more complete understanding of the system [35].

Furthermore, the polydispersity index from the Zetasizer analysis can also provide reliable information pertaining to the width of the particle size distribution. This numerical value actually expresses the uniformity in the size distribution of the nanoparticles. The current study demonstrated relatively narrow size distribution width of polydispersity index, which is $0.40 \pm 0.07$ for the solid surface functionalized cockle shell-based calcium carbonate aragonite polymorph nanoparticles in deionized water.

Apart from that, image analyses results for field emission scanning electron microscopy (FESEM) images were also in accordance with the findings obtained by the transmission electron microscope (TEM) in terms of structure, shape, and surface characterization of the surface functionalized cockle shell-based calcium carbonate aragonite nanoparticles. Indeed, the general size and shape of most cockle shellbased calcium carbonate aragonite nanoparticles were practically reduced and uniformly improved after surface modification as shown via the FESEM micrographs.

Figures 5(a) and 5(b) display the general size and surface morphology of the cockle shell-based calcium carbonate aragonite nanoparticles before surface functionalization as viewed by the field emission scanning electron microscope at different magnifications. Likewise, Figures 6(a), 6(b), and 6(c) illustrate the nanostructure of the surface functionalized cockle shell-based calcium carbonate aragonite particles viewed at various magnifications. On the other hand, Figures 7 (a) and 7(b) compare larger pictures of the overall view between both cockle shell-based calcium carbonate aragonite samples before and after surface functionalization at low magnifications, respectively.

These figures provide some evidences on the effectiveness of the milling process and also emphasize the great differences between both samples in terms of nanoparticle size and shape before and after surface modification. In fact, the overall morphological size of the surface functionalized cockle shell-based calcium carbonate aragonite nanoparticles was better compared to cockle shell-based calcium carbonate aragonite nanoparticles without surface modification as seen in the FESEM micrographs, which verified the effectiveness of the surface functionalization process on the entire nanoparticle sample. 


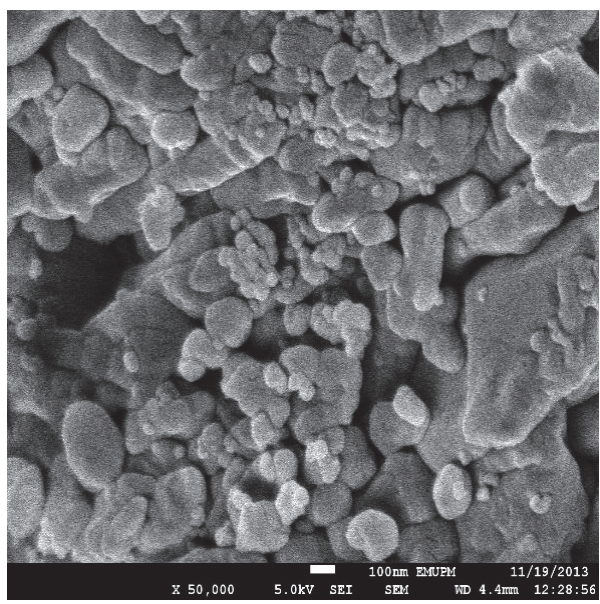

(a)

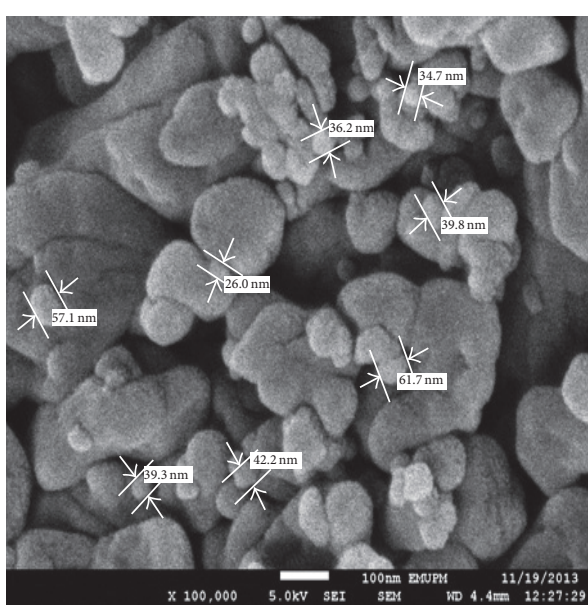

(b)

FIGURE 5: Field emission scanning electron micrographs of the cockle shell-based calcium carbonate aragonite nanoparticles before surface modification viewed at (a) 50,000x and (b) 100,000x magnifications, respectively.

On top of that, the visible rough and irregular surface, portrayed in Figure 6(c), revealed the porous characteristic of the surface functionalized cockle shell-based calcium carbonate aragonite nanoparticles in general. As mentioned earlier, calcium carbonate precipitate produced via solution precipitation reaction was also selected as one of the experimental controls. Figures $8(\mathrm{a})$ and $8(\mathrm{~b})$ portray the FESEM micrographs of calcium carbonate precipitate viewed at low and high magnifications, respectively. Both micrographs clearly display wide-ranging sizes and shapes of calcium carbonate produced by the precipitation reaction. In fact, both figures demonstrate that calcium carbonate precipitate comprised both cube-like and rounded particles.

In our opinion, cockle shell-based calcium carbonate aragonite particles had already transformed into nanosized particles while being treated via simultaneous vigorous mechanical stirring and chemical treatment in the presence of dodecyl dimethyl betaine (BS-12) during the nanoparticle synthesis. Nevertheless, based on various electron micrographs, bundles of cockle shell-based calcium carbonate particles were observed to clump together after the addition of BS-12, which may have affected their size measurement and distribution microscopically. According to Wang et al. [18], BS-12 could change surface property and lead to decreased surface energy of calcium carbonate particle which was prepared from the carbonation process in their study. However, in our study, we suggest that the BS-12 substance was not embedded in cockle shell-based calcium carbonate nanoparticles; rather, some residues of BS12 were probably adsorbed onto their surfaces throughout the synthesis process. This chemical reaction, therefore, possibly influenced the surface property of the nanoparticles, which eventually resulted in agglomeration among nanoparticles due to decreased surface energy as evidently shown earlier in most of the transmission electron micrographs of the cockle shell-based calcium carbonate aragonite nanoparticles without surface modification.
Besides the improvement in size and shape homogeneities of the nanoparticles, the dispersion among the nanoparticles also improved after surface modification as displayed in previous TEM micrographs (Figures $1(\mathrm{~b})$ and 2 ). In this regard, the good production of surface functionalized cockle shell-based calcium carbonate aragonite nanoparticles with better uniformity in size and shape might be due to the physical collision between the nanoparticles during the milling process in the surface functionalization procedure. Moreover, the method also led to the adsorption of calcium ions from calcium chloride dihydrate solution onto the surface of the nanoparticles, which possibly resulted in repulsion among the cockle shell-based calcium carbonate aragonite polymorph nanoparticles, hence improving the overall dispersion and distribution. Therefore, this method is indeed very advantageous to be exploited for many biomedical purposes, especially for drug delivery applications, to prevent nanoparticles from clumping together as any investigation on biological effects is not appropriate if the samples contain coarse agglomeration among nanoparticles [36].

3.2. Surface Functionalization. The evaluation of surface modification onto the cockle shell-based calcium carbonate aragonite polymorph nanoparticles was quantitatively investigated in terms of calcium ion adsorption during the functionalization process by employing specific instruments for calcium ion concentration measurement as described earlier. The samples were treated for 6 hours on a laboratory roller mill machine for five successive days. Measurement was taken 10 times and the values were expressed as mean \pm standard deviation for three independent batches of experiments. Table 2 displays the calcium ion concentrations in parts per million (ppm) units for five consecutive days of the surface functionalization process. On the other hand, Figure 9 portrays the total adsorption of the calcium ions concentration during 30-hour treatment period of the whole modification process onto the surface of the cockle shellbased calcium carbonate aragonite polymorph nanoparticles. 


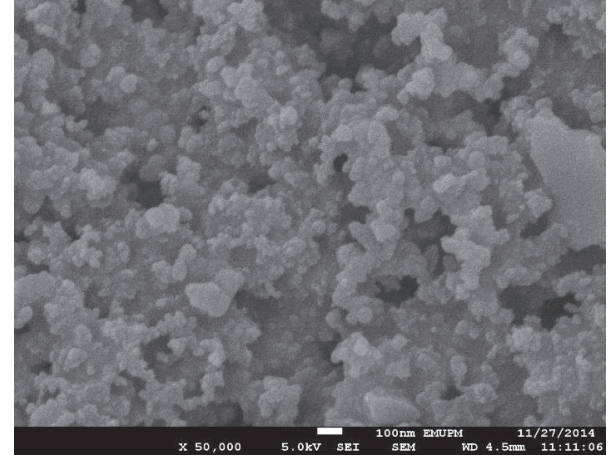

(a)

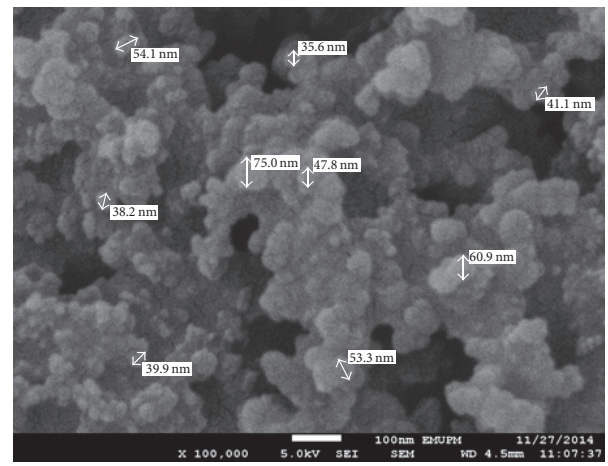

(b)

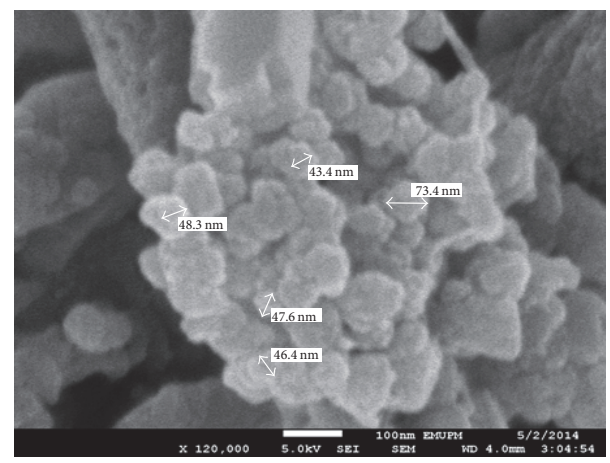

(c)

FIGURE 6: Field emission scanning electron micrographs of the surface functionalized cockle shell-based calcium carbonate aragonite nanoparticles after the milling process viewed at different magnifications of (a) 50,000x, (b) $100,000 x$, and (c) $120,000 x$, respectively.

Results revealed that there was a significant reduction in the calcium ion concentration during the five days of treatment. The initial calcium ion concentration for all experimental batches was constant, which was roughly at 972.0 ppm. Moreover, further depletion of calcium ion concentrations apparently occurred every day during the surface modification treatment, in which they were around $890.0 \pm$ $2.3 \mathrm{ppm}, 821.4 \pm 1.7 \mathrm{ppm}, 787.1 \pm 1.8 \mathrm{ppm}, 776.0 \pm 2.4 \mathrm{ppm}$, and $765.7 \pm 1.7 \mathrm{ppm}$, consecutively. The total adsorption of calcium ion onto 20 grams of cockle shell-based calcium carbonate aragonite polymorph nanoparticles after five days
TABLE 2: Measurement of calcium ion concentration (in parts per million units) during five days of surface modification treatment expressed in mean \pm standard deviation of three independent experimental batches.

\begin{tabular}{lc}
\hline $\begin{array}{l}\text { Time of } \\
\text { treatments }\end{array}$ & $\begin{array}{c}\text { Calcium ion concentrations in parts } \\
\text { per million (ppm) } \\
\text { mean } \pm \text { standard deviation }\end{array}$ \\
\hline Day 0 [initial] & $972.0 \pm 0.0$ \\
Day 1 (6 hours) & $890.0 \pm 2.3$ \\
Day 2 (12 hours) & $821.4 \pm 1.7$ \\
Day 3 (18 hours) & $787.1 \pm 1.8$ \\
Day 4 (24 hours) & $776.0 \pm 2.4$ \\
Day 5 (30 hours) & $765.7 \pm 1.7$ \\
\hline
\end{tabular}

of treatment was approximately $206.3 \mathrm{ppm}$ as clearly shown in Figure 9.

The decrease in calcium ion concentration from the solution medium indeed provides quantitative evidence portraying calcium adsorption onto the surface of cockle shellbased calcium carbonate aragonite polymorph nanoparticles during the surface functionalization process. In fact, Huang et al. [30] also reported similar result regarding calcium ion adsorption onto calcium carbonate particles, but employing different materials and methods of calcium carbonate synthesis with their distinctive experimental designs. In our opinion, the positively charged calcium ion was adsorbed onto the surface of the cockle shell-based calcium carbonate aragonite polymorph nanoparticles during the milling process and, therefore, possibly resulted in better dispersion of nanoparticles, practically due to electrostatic stabilization among the nanoparticles as clearly shown in the TEM micrographs earlier.

3.3. Surface Properties and Calcium Carbonate Polymorphism. In the study, the surface functionalized cockle shell-based calcium carbonate aragonite polymorph nanoparticle was synthesized in the presence of dodecyl dimethyl betaine (BS-12). The surface modification process was performed to functionalize the surface and improve the overall size distribution and dispersion of the nanoparticles. The influence of the BS-12 compound and the functionalization process on the surface properties of the cockle shell-based calcium carbonate aragonite polymorph nanoparticles were thus investigated in terms of $\mathrm{pH}$ change and chemical analysis via Fourier Transmission Infrared (FTIR) spectroscopy as shown in Table 3 and Figure 10, respectively. The pH measurement was performed ten times and the value was expressed as mean \pm standard deviation. In addition, their effects on calcium carbonate polymorphism were also investigated and compared through FTIR spectroscopy and X-ray powder diffraction (XRD) analyses.

3.3.1. $\mathrm{pH}$ Analysis. The initial $\mathrm{pH}$ measurement of the cockle shell-based calcium carbonate aragonite particles was $\mathrm{pH}$ $8.59 \pm 0.01$, whereas the $\mathrm{pH}$ of pure BS-12 solution was found to be 6.4. After the addition of $1.5 \mathrm{~mL}$ of BS-12 to the synthesis 


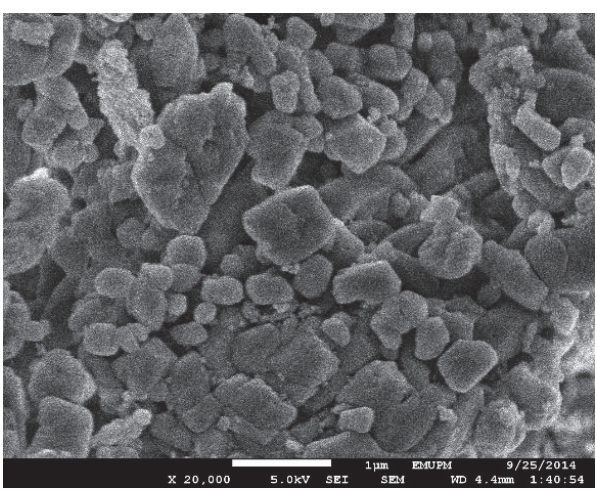

(a)

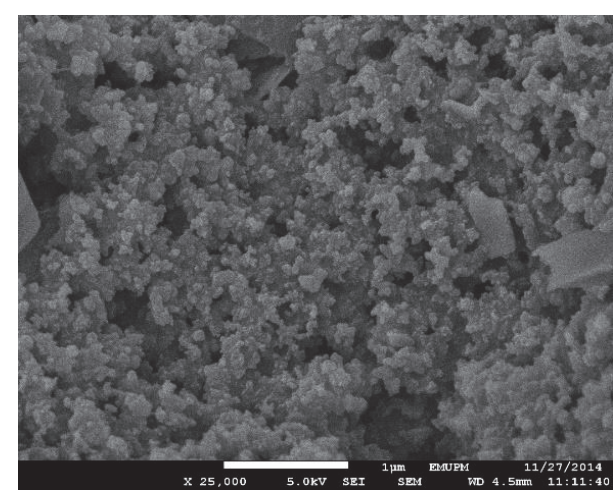

(b)

FIGURE 7: FESEM micrographs showing an overview of (a) cockle shell-based calcium carbonate aragonite nanoparticles before surface modification and (b) surface functionalized cockle shell-based calcium carbonate aragonite nanoparticles viewed at low magnifications of $20,000 x$ and 25,000x, respectively.

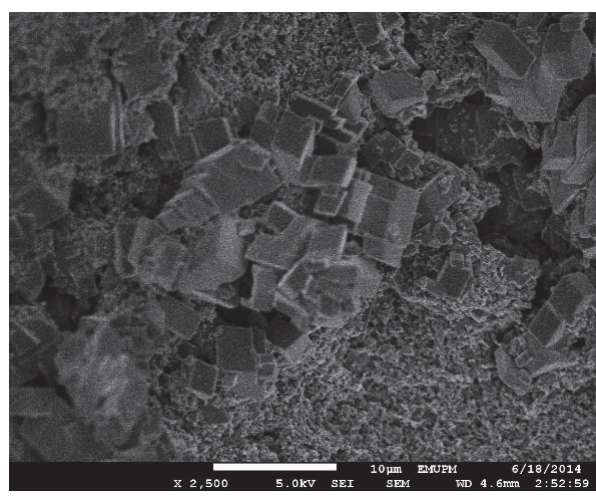

(a)

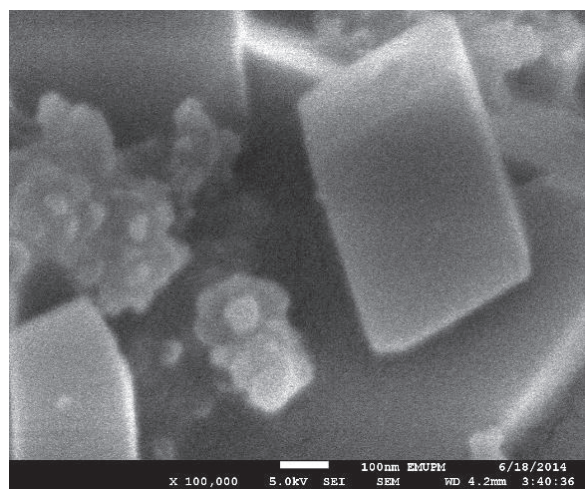

(b)

FIGURE 8: Mixture of cube-like and round-shaped calcium carbonate nanoparticles produced by the solution route of precipitation reaction with various sizes examined by field emission scanning electron microscope at (a) 2,500x and (b) 100,000x magnifications, respectively.

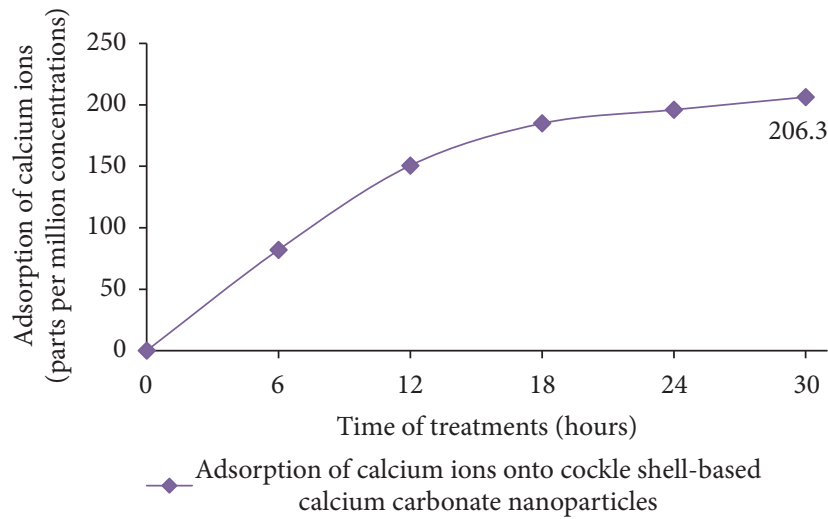

FIGURE 9: Adsorption of calcium ion onto the surface of cockle shellbased calcium carbonate aragonite polymorph nanoparticles during 30-hour treatment period of surface functionalization process.

process, the $\mathrm{pH}$ of the cockle shell-based calcium carbonate aragonite particles was reduced to $\mathrm{pH} 8.38 \pm 0.01$ even though the sample had been washed thoroughly for several times
TABLE 3: $\mathrm{pH}$ measurement of each sample expressed in mean \pm standard deviation measured by a $\mathrm{pH}$ meter.

\begin{tabular}{lc}
\hline Sample & $\mathrm{pH}$ \\
\hline $\begin{array}{l}\text { Cockle shell-based calcium carbonate } \\
\text { aragonite microparticles (before addition of BS-12) }\end{array}$ & $8.59 \pm 0.01$ \\
$\begin{array}{l}\text { Cockle shell-based calcium carbonate } \\
\text { aragonite nanoparticles (after addition of BS-12) }\end{array}$ & $8.38 \pm 0.01$ \\
$\begin{array}{l}\text { Surface functionalized cockle shell-based calcium } \\
\text { carbonate aragonite nanoparticles }\end{array}$ & $7.85 \pm 0.01$ \\
$\begin{array}{l}\text { Dodecyl dimethyl betaine (BS-12) } \\
\text { Calcium chloride dihydrate of 1000 ppm }\end{array}$ & $6.40 \pm 0.00$ \\
concentrations & $7.05 \pm 0.01$ \\
\hline
\end{tabular}

with distilled water to wash out the residual BS-12 compound from the whole sample. In our opinion, $\mathrm{pH}$ reduction in the cockle shell-based calcium carbonate aragonite particles indicates that some residues of BS-12 substance might have probably remained and adsorbed onto the surface of the nanoparticles. 


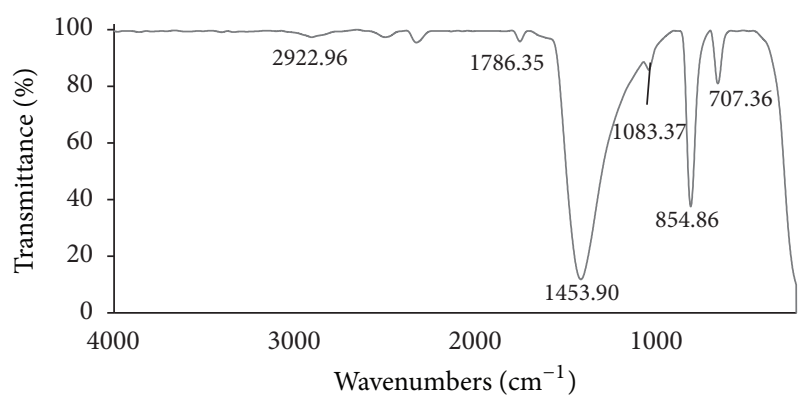

— Micron-sized cockle shell-based $\mathrm{CaCO}_{3}$

(a)

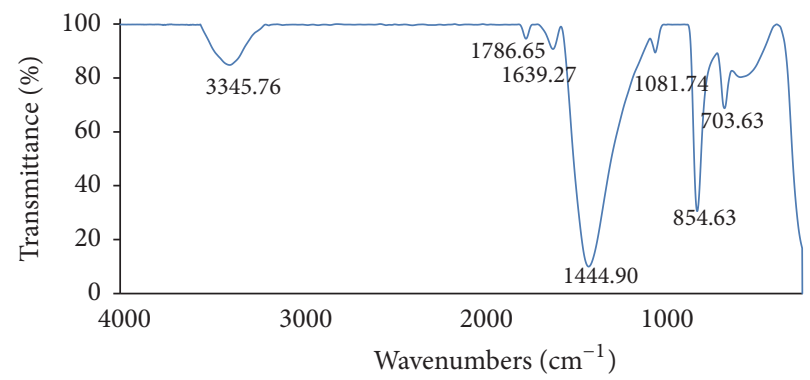

_ Nanosized cockle shell-based $\mathrm{CaCO}_{3}$ before surface modification

(b)

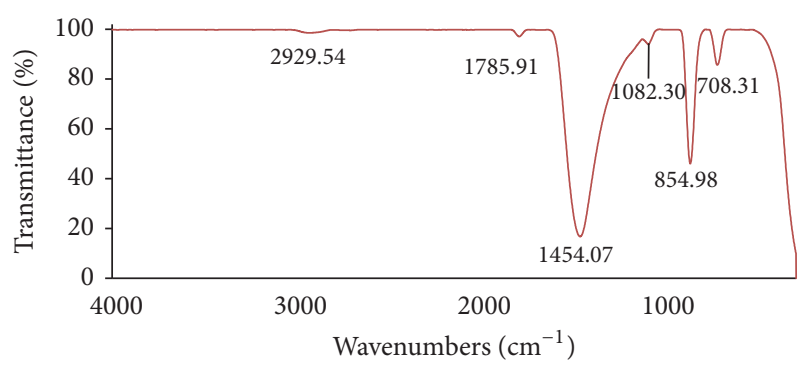

— Nanosized cockle shell-based $\mathrm{CaCO}_{3}$ after surface modification

(c)

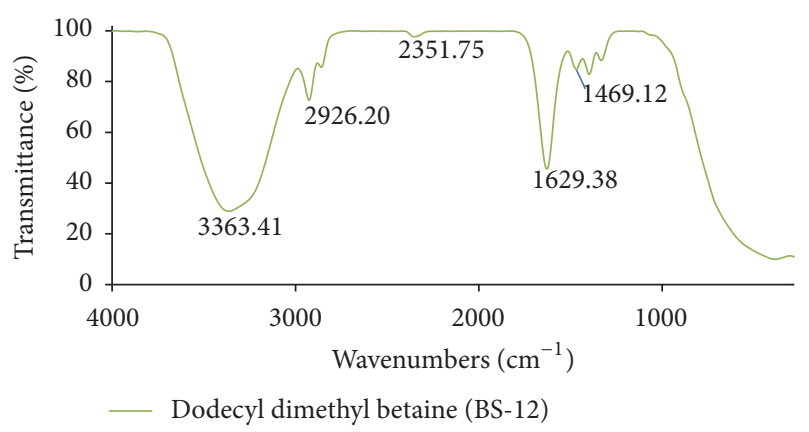

(d)

FIGURE 10: FTIR spectra of samples. (a) Micron-sized cockle shellbased calcium carbonate particles before addition of BS-12. (b) Nanosized cockle shell-based calcium carbonate particles after BS12 addition. (c) Surface functionalized cockle shell-based calcium carbonate nanoparticles. (d) Dodecyl dimethyl betaine (BS-12).

Apart from that, there was a further decrease in $\mathrm{pH}$ of the cockle shell-based calcium carbonate aragonite nanoparticles to $\mathrm{pH} 7.85 \pm 0.01$ after the surface functionalization process into $1000 \mathrm{ppm}$ of calcium chloride dihydrate solution, which measured at $\mathrm{pH} 7.05 \pm 0.01$. In this case, the huge $\mathrm{pH}$ reduction from $\mathrm{pH} 8.38 \pm 0.01$ to $\mathrm{pH} 7.85 \pm 0.01$ of the cockle shell-based calcium carbonate aragonite nanoparticles was possibly due to the adsorption of calcium ion from calcium chloride dihydrate solution onto the surface of the nanoparticles during the surface functionalization process. Moreover, these data are supported by the results obtained via FTIR spectroscopy analysis as displayed in Figure 10.

3.3.2. FTIR Spectra Analysis. Figure 10 portrays the FTIR spectra of four different samples, which are cockle shell-based calcium carbonate aragonite microparticles without BS-12 treatment, cockle shell-based calcium carbonate aragonite nanoparticles after addition of BS-12 before surface modification procedure, cockle shell-based calcium carbonate aragonite nanoparticles after surface modification, and pure dodecyl dimethyl betaine solution (BS-12). Based on the figure, additional vibration frequencies were evidently observed at $3345 \mathrm{~cm}^{-1}$ and $1639 \mathrm{~cm}^{-1}$ for the cockle shell-based calcium carbonate nanoparticles sample after the addition of BS-12 as shown in Figure 10(b) compared to the spectral data of the cockle shell-based calcium carbonate microparticles in Figure 10(a). Similar positional bands were also observed at $3363 \mathrm{~cm}^{-1}$ and $1629 \mathrm{~cm}^{-1}$ representing the amine functional groups of dodecyl dimethyl betaine (BS-12) as portrayed in Figure 10(d). In our opinion, the additional peaks in the cockle shell-based calcium carbonate nanoparticles were consistent with the presence of N-H bend in the BS-12 compound, hence evidencing the absorption of some BS-12 residues onto the surface of the cockle shell-based calcium carbonate nanoparticles during the synthesis reaction.

However, those additional bands were absent in the FTIR spectra of the surface functionalized cockle shell-based calcium carbonate nanoparticles as clearly seen in Figure 10(c). In this regard, the surface functionalization process was deemed as a neutralization procedure that might have chemically improved the surface properties of cockle shell-based calcium carbonate nanoparticles via positional adjustment of some functional groups in the sample by returning to almost similar positional phase as seen in the spectral data of the micron-sized cockle shell-based calcium carbonate particles in Figure 10(a). Meanwhile, the absorption peak that appeared just below $3000 \mathrm{~cm}^{-1}$ demonstrates the presence of $\mathrm{C}-\mathrm{H}$ stretch, which was observed in both cockle shell-based calcium carbonate microparticles and surface functionalized cockle shell-based calcium carbonate nanoparticle samples at $2922 \mathrm{~cm}^{-1}$ and $2929 \mathrm{~cm}^{-1}$, respectively.

In addition, the position of carbonate groups has been well documented to play a significant role in determining the phase of calcium carbonate polymorphism. In general, analysis of calcium carbonate phase is basically based on the evidences associated with four common vibrational modes of FTIR bands which are symmetric stretching $V_{1}$, outof-plane bending $V_{2}$, doubly degenerate planar asymmetric $V_{3}$, and doubly degenerate planar bending $V_{4}[9,10]$. Broad bands of FTIR spectra related to carbonate groups 
were found at $1786 \mathrm{~cm}^{-1}, 1453 \mathrm{~cm}^{-1}, 1083 \mathrm{~cm}^{-1}, 854 \mathrm{~cm}^{-1}$, and $707 \mathrm{~cm}^{-1}$ in the micron-sized cockle shell-based calcium carbonate sample and $1786 \mathrm{~cm}^{-1}, 1444 \mathrm{~cm}^{-1}, 1081 \mathrm{~cm}^{-1}$, $854 \mathrm{~cm}^{-1}$, and $703 \mathrm{~cm}^{-1}$ in the cockle shell-based calcium carbonate nanoparticle after addition of BS-12 as well as at $1785 \mathrm{~cm}^{-1}, 1454 \mathrm{~cm}^{-1}, 1082 \mathrm{~cm}^{-1}, 854 \mathrm{~cm}^{-1}$, and $708 \mathrm{~cm}^{-1}$ in the cockle shell-based calcium carbonate nanoparticle sample after surface modification. The FTIR spectral data obtained were indeed common characteristics of carbonate groups generally found in calcium carbonate compound as reported by other studies [7-10, 21, 26].

On the other hand, the out-of-plane $\mathrm{C}-\mathrm{O}$ bending $V_{2}$ mode of carbonate groups was observed at respective $854 \mathrm{~cm}^{-1}$ band in all cockle shell-based calcium carbonate samples. Meanwhile, the observed band at $1083 \mathrm{~cm}^{-1}$ in the micron-sized cockle shell-based calcium carbonate, $1081 \mathrm{~cm}^{-1}$ in the cockle shell-based calcium carbonate nanoparticle after addition of BS-12, and $1082 \mathrm{~cm}^{-1}$ in the surface functionalized cockle shell-based calcium carbonate samples were assigned as symmetric stretching $V_{1}$ mode of carbonate groups in calcium carbonate substance. Furthermore, the presence of carbonate groups was also associated with $\mathrm{C}-\mathrm{O}$ stretching mode in a broad doubly degenerate asymmetric band $V_{3}$ region from $1600 \mathrm{~cm}^{-1}$ to $1400 \mathrm{~cm}^{-1}$ with the appearance of prominent FTIR peaks at $1453 \mathrm{~cm}^{-1}$, $1444 \mathrm{~cm}^{-1}$, and $1454 \mathrm{~cm}^{-1}$ in the FTIR spectra of three different cockle shell-based calcium carbonate samples as portrayed in Figures 10(a), 10(b), and 10(c), respectively. Indeed, the presence of FTIR bands from $1600 \mathrm{~cm}^{-1}$ to $1400 \mathrm{~cm}^{-1}$ and $1081 \mathrm{~cm}^{-1}$ to $1083 \mathrm{~cm}^{-1}$ as well as $854 \mathrm{~cm}^{-1}$ specifically indicates the aragonite phase of calcium carbonate as confirmed in many literatures [7-10, 21].

Apart from that, the doubly degenerate bending $V_{4}$ peak of carbonate groups was observed at $707 \mathrm{~cm}^{-1}$ in the micronsized cockle shell-based calcium carbonate, at $703 \mathrm{~cm}^{-1}$ in the cockle shell-based calcium carbonate nanoparticles, and at $708 \mathrm{~cm}^{-1}$ in the surface functionalized cockle shellbased calcium carbonate samples. The appearance of doubly degenerate bending $V_{4}$ peaks of carbonate groups was also reported to be attributed to the aragonite phase of calcium carbonate compound [9]. In fact, these FTIR findings are in good agreement with the results reported in other studies $[7,8,21]$ pertaining to carbonate group positions in calcium carbonate compound specifically derived from cockle shells, hence verifying its predominant aragonite phase of calcium carbonate polymorphism in particular. Furthermore, FTIR analysis also concluded that the surface functionalization process did not change or alter the aragonite phase of calcium carbonate nanoparticles derived from cockle shells. These findings were further justified through XRD analysis shown in Figure 11.

3.3.3. XRD Pattern Analysis. In general, the crystalline phase of the samples can be identified using an X-ray powder diffractometer analytical instrument. The intact and strong crystallization state of the cockle shell-based calcium carbonate nanoparticles before surface functionalization and the surface functionalized cockle shell-based calcium carbonate

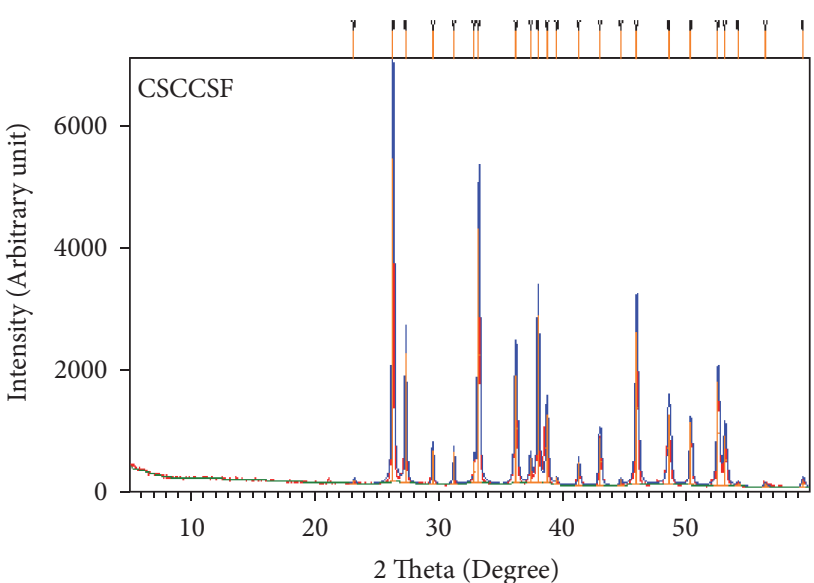

(a)

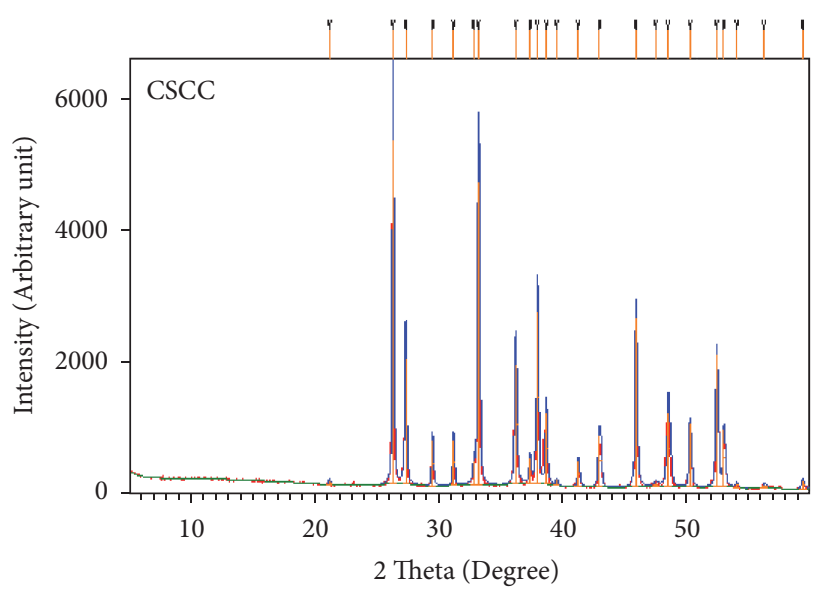

(b)

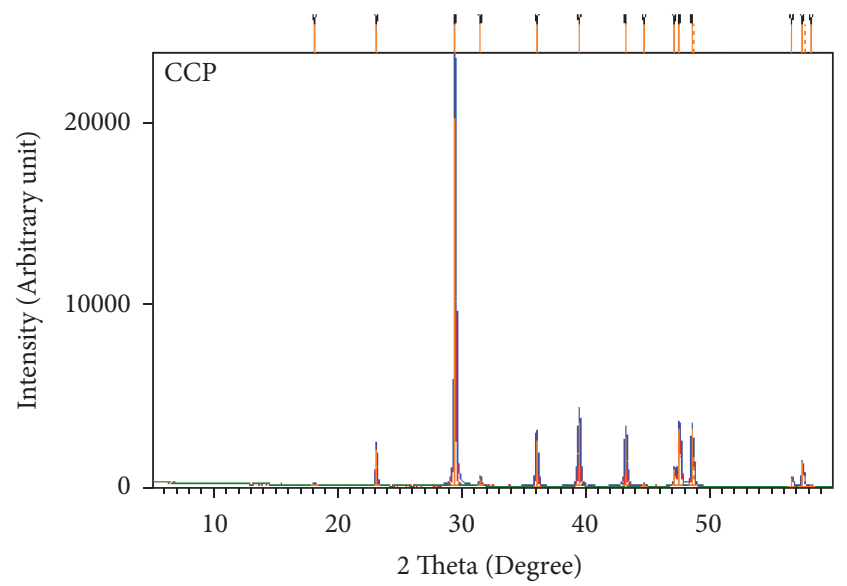

(c)

FIGURE 11: X-ray diffraction patterns of (a) cockle shell-based calcium carbonate nanoparticles before surface functionalization, (b) surface functionalized cockle shell-based calcium carbonate nanoparticles, and (c) precipitated calcium carbonate.

as well as the sample control, which is calcium carbonate produced from precipitation, were observed corresponding to the XRD patterns as shown in Figures 11(a), 11(b), and 11(c), respectively. However, similar pattern of XRD patterns 
could only be observed in the cockle shell-based calcium carbonate nanoparticles before surface functionalization and the surface functionalized cockle shell-based calcium carbonate samples, but not in the case of precipitated calcium carbonate sample.

The XRD patterns of both cockle shell-based calcium carbonate samples before and after surface functionalization were indeed matched with the characteristic peaks of the aragonite phase JCPDS file number 00-041-1475. In fact, the XRD patterns of the cockle shell-based calcium carbonate nanoparticle before surface functionalization were in accordance with the previous result reported by Islam et al. [7, 8]. The addition of BS-12 as surfactant apparently did not alter or influence the aragonite phase of cockle shell-based calcium carbonate nanoparticles during the synthesis reaction as seen in Figure 11(a). Moreover, there was no change in the XRD pattern of the surface functionalized cockle shell-based calcium carbonate nanoparticles, which indicates that the surface modification process had maintained the crystalline nature of aragonite phase in its cockle shell powder sample (Figure 11(b)). There was no additional peak by other impurities observed in the XRD spectra of both cockle shell-based calcium carbonate samples as well, neither after adding BS-12 nor after the surface modification process. This demonstrates that those particular products have high purity content of aragonite polymorph. Therefore, these findings also validated the earlier FTIR results.

In contrast, all relative sharp peaks at $2 \theta$-positions exhibited by the precipitated calcium carbonate sample were typically indexed as calcite phase of calcium carbonate corresponding to JCPDS file number 00-047-1743. The different XRD pattern of the rhombohedral calcite characteristics exhibited by the precipitated calcium carbonate sample depicted that the experimental control was comprised of calcium carbonate calcite phase rather than aragonite polymorph as seen in Figures 11(a), 11(b), and 11(c), respectively.

\section{Conclusion}

Some cockle shell-based calcium carbonate aragonite polymorph particles have already been transformed into nanosized particles during simultaneous vigorous mechanical stirring process and chemical treatment by dodecyl dimethyl betaine (BS-12). Nevertheless, the effect of BS-12 surfactant possibly caused higher tendency of clumping together among cockle shell-based calcium carbonate particles, hence affecting their size distribution measurements as well as the nanoparticles' dispersion in general. Apparently, the modification method led to calcium ion adsorption onto the surface of the nanoparticles, resulting in repulsion among the cockle shell-based calcium carbonate aragonite polymorph nanoparticles. In this regard, the surface functionalized cockle shell-based calcium carbonate aragonite nanoparticles improved the general dispersion and distribution between the nanoparticles in the study. Furthermore, surface functionalization also led to high homogeneity production of the nanoparticles in terms of better size and morphology, which was possibly due to physical collision between the particles during the milling process throughout the surface functionalization procedure. The adopted surface functionalization method for cockle shell-based calcium carbonate nanoparticle synthesis was also verified to preserve its aragonite crystalline composition during the whole process. The development of surface functionalized cockle shell-based calcium carbonate nanoparticles synthesis method with improved characteristics is indeed a practical, convenient, and environmentally friendly synthesis method for large scale production of calcium carbonate aragonite polymorph nanoparticles derived from naturally occurring cockle shell by-product with high uniformity in size and shape, which can offer vast array of potentials for diverse industrial applications, especially in the biomedical field today.

\section{Disclosure}

The authors confirm that the paper has been read and approved by all the names listed as authors.

\section{Competing Interests}

The authors declare that there is no conflict of interests associated with this paper submitted for publication.

\section{References}

[1] J. Awang-Hazmi, A. B. Z. Zuki, M. M. Nordin, A. Jalila, and Y. Norimah, "Mineral composition of the cockle (Anadara Granosa) shells of west coast of peninsular Malaysia and its potential as biomaterial for use in bone repair," Journal of Animal and Veterinary Advances, vol. 6, no. 5, pp. 591-594, 2007.

[2] G. Falini, S. Albeck, S. Weiner, and L. Addadi, "Control of aragonite or calcite polymorphism by mollusk shell macromolecules," Science, vol. 271, no. 5245, pp. 67-69, 1996.

[3] R. M. Santos, M. Bodor, P. N. Dragomir, A. G. Vraciu, M. Vlad, and T. Van Gerven, "Magnesium chloride as a leaching and aragonite-promoting self-regenerative additive for the mineral carbonation of calcium-rich materials," Minerals Engineering, vol. 59, pp. 71-81, 2014.

[4] A. B. Z. Zakaria, N. Zakaria, and Z. Kasim, "Mineral composition of the cockle (anadara granosa) shells, hard clamps (meretrix meretrix) shells and corals (porites. spp): a comparative study," Journals of Animals and Veterinary Advances, vol. 3, no. 7, pp. 445-447, 2004.

[5] G. Li, Z. Li, and H. Ma, "Synthesis of aragonite by carbonization from dolomite without any additives," International Journal of Mineral Processing, vol. 123, pp. 25-31, 2013.

[6] Z. Hu, M. Shao, Q. Cai et al., "Synthesis of needle-like aragonite from limestone in the presence of magnesium chloride," Journal of Materials Processing Technology, vol. 209, no. 3, pp. 1607-1611, 2009.

[7] K. N. Islam, M. Z. B. A. Bakar, M. M. Noordin, M. Z. B. Hussein, N. S. B. A. Rahman, and M. E. Ali, "Characterisation of calcium carbonate and its polymorphs from cockle shells (Anadara granosa)," Powder Technology, vol. 213, no. 1, pp. 188-191, 2011.

[8] K. N. Islam, Z. B. Abu Bakar, M. E. Ali et al., "A novel method for the synthesis of calcium carbonate (aragonite) nanoparticles from cockle shells," Powder Technology, vol. 235, pp. 70-75, 2013. 
[9] A. Shafiu Kamba, M. Ismail, T. A. Tengku Ibrahim, and Z. A. B. Zakaria, "Synthesis and characterisation of calcium carbonate aragonite nanocrystals from cockle shell powder (Anadara granosa)," Journal of Nanomaterials, vol. 2013, Article ID 398357, 9 pages, 2013.

[10] H. Bharatham, M. Z. A. B. Zakaria, E. K. Perimal, L. M. Yusof, and M. Hamid, "Mineral and physiochemical evaluation of Cockle shell (Anadara granosa) and other selected Molluscan shell as potential biomaterials," Sains Malaysiana, vol. 43, no. 7, pp. 1023-1029, 2014.

[11] C. Wang, J. Zhao, X. Zhao, H. Bala, and Z. Wang, "Synthesis of nanosized calcium carbonate (aragonite) via a polyacrylamide inducing process," Powder Technology, vol. 163, no. 3, pp. 134$138,2006$.

[12] M. Kitamura, "Controlling factor of polymorphism in crystallization process," Journal of Crystal Growth, vol. 237-239, no. 14, pp. 2205-2214, 2002.

[13] H. Guo, Z. Qin, P. Qian, P. Yu, S. Cui, and W. Wang, "Crystallization of aragonite $\mathrm{CaCO}_{3}$ with complex structures," Advanced Powder Technology, vol. 22, no. 6, pp. 777-783, 2011.

[14] A. Rizzuti and C. Leonelli, "Crystallization of aragonite particles from solution under microwave irradiation," Powder Technology, vol. 186, no. 3, pp. 255-262, 2008.

[15] G. Yan, L. Wang, and J. Huang, “The crystallization behavior of calcium carbonate in ethanol/water solution containing mixed nonionic/anionic surfactants," Powder Technology, vol. 192, no. 1, pp. 58-64, 2009.

[16] O. Söhnel and J. W. Mullin, "Precipitation of calcium carbonate," Journal of Crystal Growth, vol. 60, no. 2, pp. 239-250, 1982.

[17] N. Koga, D. Kasahara, and T. Kimura, "Aragonite crystal growth and solid-state aragonite-calcite transformation: a physicogeometrical relationship via thermal dehydration of included water," Crystal Growth \& Design, vol. 13, no. 5, pp. 2238-2246, 2013.

[18] C. Wang, Y. Liu, H. Bala et al., "Facile preparation of $\mathrm{CaCO} 3$ nanoparticles with self-dispersing properties in the presence of dodecyl dimethyl betaine," Colloids and Surfaces A: Physicochemical and Engineering Aspects, vol. 297, no. 1-3, pp. 179-182, 2007.

[19] J. Sargheini, A. Ataie, S. M. Salili, and A. A. Hoseinion, "Onestep facile synthesis of $\mathrm{CaCO} 3$ nanoparticles via mechanochemical route," Powder Technology, vol. 219, pp. 72-77, 2012.

[20] A. B. Z. Zakaria, B. F. Hussein, and M. M. Noordin, "Cockle shell-based biocomposite scaffold for bone tissue engineering," in Regenerative Medicine and Tissue Engineering-Cells and Biomaterials, vol. 2011, pp. 365-390, INTECH, Rijeka, Croatia, 2011.

[21] K. N. Islam, A. B. Z. Zuki, M. E. Ali et al., "Facile synthesis of calcium carbonate nanoparticles from cockle shells," Journal of Nanomaterials, vol. 2012, Article ID 534010, 5 pages, 2012.

[22] A. S. Kamba, M. Ismail, T. A. T. Ibrahim, and Z. A. B. Zakaria, "A $\mathrm{pH}$-sensitive, biobased calcium carbonate aragonite nanocrystal as a novel anticancer delivery system," BioMed Research International, vol. 2013, Article ID 587451, 10 pages, 2013.

[23] S. I. Stupp and P. V. Braun, "Molecular manipulation of microstructures: biomaterials, ceramics, and semiconductors," Science, vol. 277, no. 5330, pp. 1242-1248, 1997.

[24] J. Yu, M. Lei, B. Cheng, and X. Zhao, "Facile preparation of calcium carbonate particles with unusual morphologies by precipitation reaction," Journal of Crystal Growth, vol. 261, no. 4, pp. 566-570, 2004
[25] Z. Hu and Y. Deng, "Synthesis of needle-like aragonite from calcium chloride and sparingly soluble magnesium carbonate," Powder Technology, vol. 140, no. 1-2, pp. 10-16, 2004.

[26] L. Saidykhan, M. Z. B. Abu Bakar, Y. Rukayadi, A. U. Kura, and S. Y. Latifah, "Development of nanoantibiotic delivery system using cockle shell-derived aragonite nanoparticles for treatment of osteomyelitis," International Journal of Nanomedicine, vol. 11, pp. 661-673, 2016.

[27] Y. Ueno, H. Futagawa, Y. Takagi, A. Ueno, and Y. Mizushima, "Drug-incorporating calcium carbonate nanoparticles for a new delivery system," Journal of Controlled Release, vol. 103, no. 1, pp. 93-98, 2005.

[28] H. V. Tran, L. D. Tran, H. D. Vu, and H. Thai, "Facile surface modification of nanoprecipitated calcium carbonate by adsorption of sodium stearate in aqueous solution," Colloids and Surfaces A: Physicochemical and Engineering Aspects, vol. 366, no. 1-3, pp. 95-103, 2010.

[29] Z. P. Xu, Q. H. Zeng, G. Q. Lu, and A. B. Yu, "Inorganic nanoparticles as carriers for efficient cellular delivery," Chemical Engineering Science, vol. 61, no. 3, pp. 1027-1040, 2006.

[30] Y. C. Huang, F. M. Fowkes, T. B. Lloyd, and N. D. Sanders, "Adsorption of calcium ions from calcium chloride solutions onto calcium carbonate particles," Langmuir, vol. 7, no. 8, pp. $1742-1748,1991$.

[31] M.-G. Song, J.-Y. Kim, and J.-D. Kim, "Effect of sodium stearate and calcium ion on dispersion properties of precipitated calcium carbonate suspensions," Colloids and Surfaces A: Physicochemical and Engineering Aspects, vol. 229, no. 1-3, pp. 75-83, 2003.

[32] S. M. El-Sheikh, S. El-Sherbiny, A. Barhoum, and Y. Deng, "Effects of cationic surfactant during the precipitation of calcium carbonate nano-particles on their size, morphology, and other characteristics," Colloids and Surfaces A: Physicochemical and Engineering Aspects, vol. 422, pp. 44-49, 2013.

[33] N. Qiu, H. Yin, B. Ji et al., "Calcium carbonate microspheres as carriers for the anticancer drug camptothecin," Materials Science and Engineering C, vol. 32, no. 8, pp. 2634-2640, 2012.

[34] P. Liang, D. Zhao, C.-Q. Wang, J.-Y. Zong, R.-X. Zhuo, and S.$\mathrm{X}$. Cheng, "Facile preparation of heparin $/ \mathrm{CaCO}_{3} / \mathrm{CaP}$ hybrid nano-carriers with controllable size for anticancer drug delivery," Colloids and Surfaces B: Biointerfaces, vol. 102, pp. 783-788, 2013.

[35] K. W. Powers, S. C. Brown, V. B. Krishna, S. C. Wasdo, B. M. Moudgil, and S. M. Roberts, "Research strategies for safety evaluation of nanomaterials. Part VI. characterization of nanoscale particles for toxicological evaluation," Toxicological Sciences, vol. 90, no. 2, pp. 296-303, 2006.

[36] P. Bihari, M. Vippola, S. Schultes et al., "Optimized dispersion of nanoparticles for biological in vitro and in vivo studies," Particle and Fibre Toxicology, vol. 5, article no. 14, 2008. 

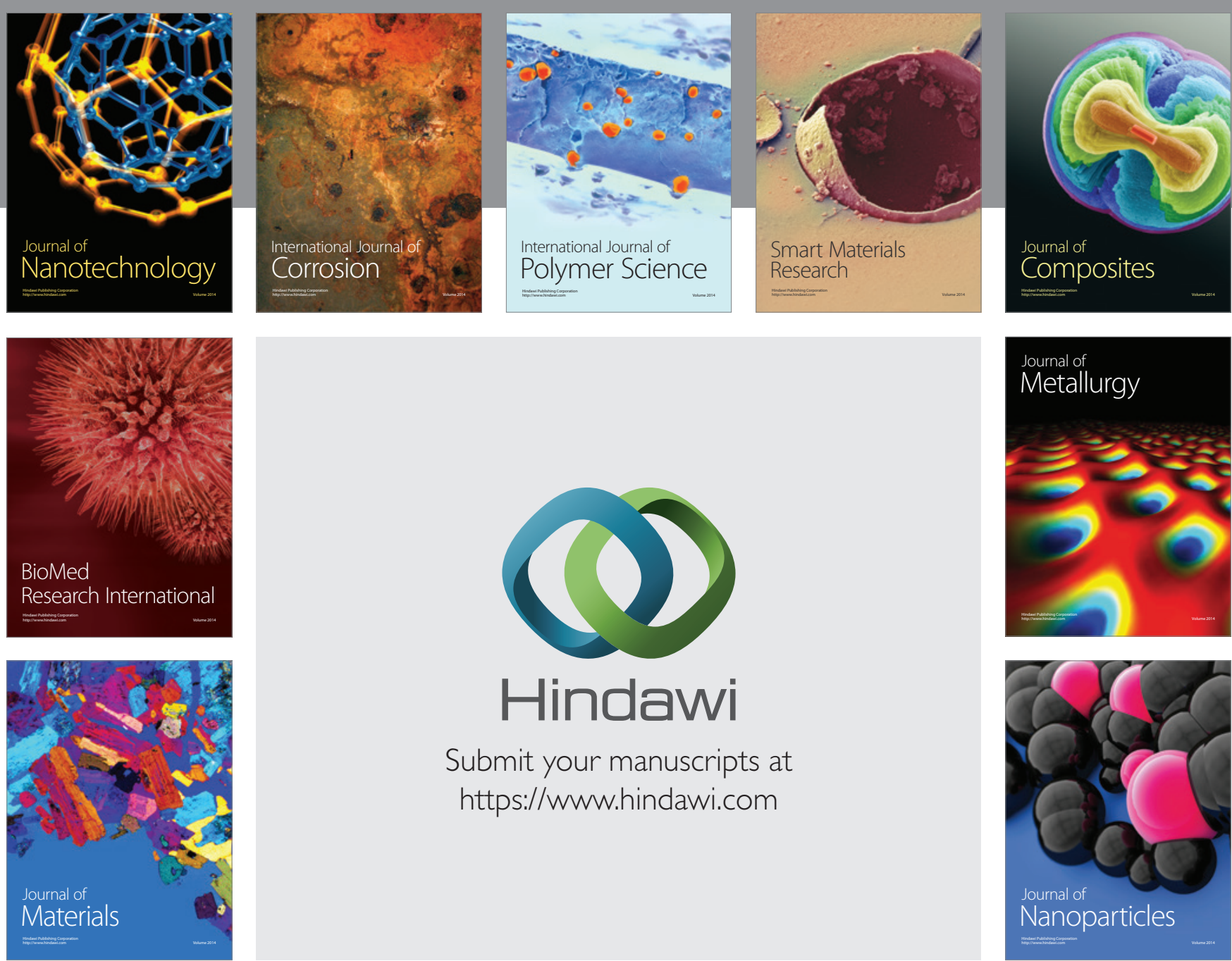

\section{Hindawi}

Submit your manuscripts at

https://www.hindawi.com

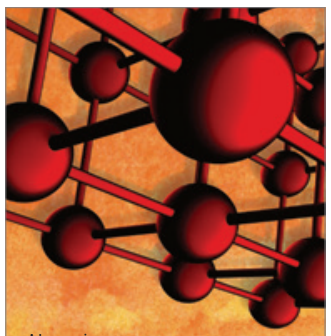

Materials Science and Engineering
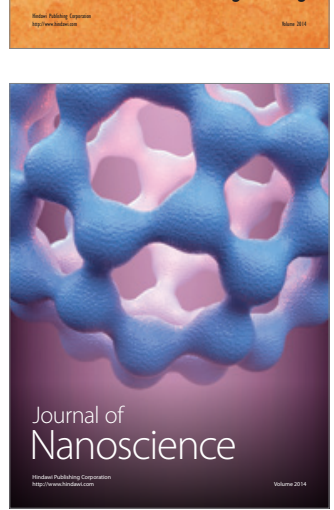
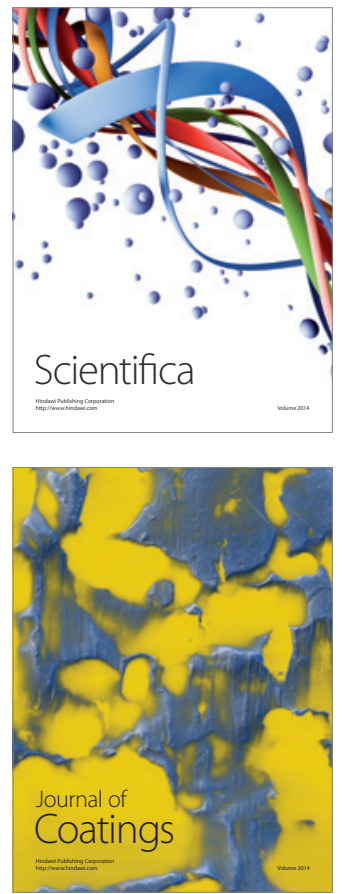
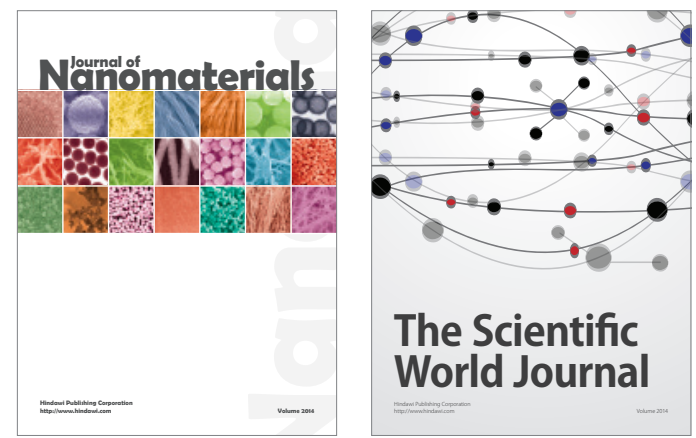

The Scientific World Journal
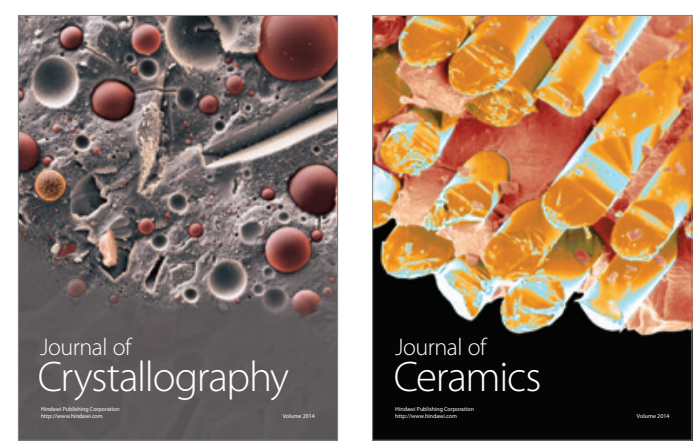
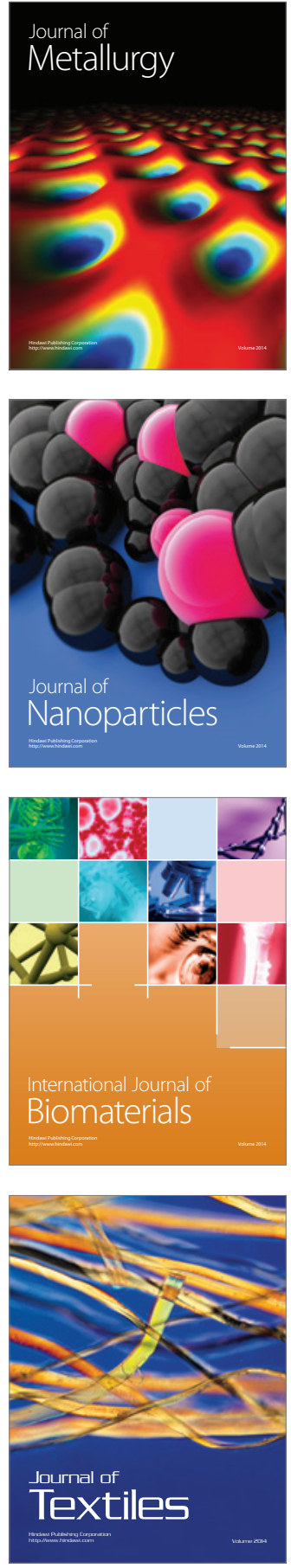